\title{
Mapeamento Genético e Caracterização Fenotípica do Mutante Anêmico Induzido por Ethyl-nitroso- urea
}

\section{CAROLINA CAVALCANTE DA CRUZ}

\author{
Dissertação apresentada ao \\ Programa de Pós-Graduação \\ Interunidades em Biotecnologia \\ USP/Instituto Butantan/ IPT, \\ para obtenção do Título de \\ Mestre em Biotecnologia. \\ Área de concentração: \\ Biotecnologia \\ Orientadora: \\ Dra. Silvia Maria Gomes \\ Massironi
}

São Paulo 


\section{RESUMO}

CRUZ, C.C. Mapeamento Genético e Caracterização Fenotípica do Mutante Anêmico Induzido por Ethyl-nitroso-urea. 2009. 103 f. Dissetação (Mestrado em Biotecnologia) Instituto de Ciências Biomédicas, Universidade de São Paulo, São Paulo, 2009.

A mutagênese química utilizando o agente mutagênico ENU ( $N$-ethyl-N-nitrosourea) seguida da observação do fenótipo deu origem ao mutante Anêmico que, logo após o nascimento apresentou coloração pálida e um menor tamanho que os camundongos normais da mesma ninhada. O tipo de herança é autossômica dominante, com morte intra útero dos mutantes homozigotos. Após o estabelecimento da linhagem mutante em fundo BALB/c, foram cruzados para o mapeamento genético camundongos BALB/c Anêmicos (Anem/+) e C57BL/6 (+/+) que geraram mutantes híbridos $\mathrm{F} 1$, que retrocruzados com seu parental normal deram origem à geração $\mathrm{N} 2$, utilizada no mapeamento. A identificação dos animais heterozigotos Anêmicos foi feita pela contagem de reticulócitos, que evidencia uma grande reticulocitose conseqüência da anemia hemolítica crônica. Para a caracterização fenotípica do mutante Anêmico foram analisados parâmetros hematológicos, além da análise de bilirrubina direta e total; ferro sérico e capacidade de ligação do ferro; análise histológica da medula óssea, baço, fígado, rim e fetos de 18 dias; análise morfológica dos eritrócitos através da microscopia eletrônica de varredura. $\mathrm{Na}$ análise imunológica foi feito o ensaio hemolítico do Sistema Complemento. Técnicas de hemostasia também foram realizadas como tempo de protrombina e tempo de tromboplastina parcial ativada. A Eletroforese de hemoglobina foi realizada para detectar deficiências na produção da mesma. O mutante Anêmico apresenta esplenomegalia, reticulocitose e policromasia acentuada, que indica a existência de anemia hemolítica crônica e aumento da eritropoiese, resposta normal à anemia e hipoxemia causando assim uma liberação precoce das células da medula óssea, assim como uma marcante microcitose e hipocromia acentuada, deixando clara a deficiência na síntese de hemoglobina. A análise histológica apresentou hemossiderose em todos os órgãos analisados e eritropoiese extramedular no baço e no fígado. O mapeamento genético foi feito utilizando-se marcadores microssatélites, sendo selecionados marcadores polimórficos entre as linhagens BALB/C e C57BL/6 envolvidas no mapeamento. Estabeleceu-se um painel de microssatélites distribuídos por todo o genoma do camundongo, que permitisse a localização do cromossomo portador da mutação. Inicialmente, foi encontrada uma forte ligação entre o gene mutante e os marcadores no cromossomo 7. A seguir foram feitos testes adicionais utilizando-se mais marcadores do mesmo cromossomo com o objetivo de estabelecer uma ligação com alto grau de confiança. $\mathrm{Na}$ procura de recombinantes que indicassem um candidato posicional, os marcadores D7Mit301 e D7Mit131 entre 46,5cM e 51cM evidenciaram um intervalo de $4,5 \mathrm{cM}$ contendo 106 genes de funções conhecidas. Através das análises fenotípicas do mutante Anêmico e estudo dos genes candidatos neste intervalo, o gene $\mathrm{Hbb}$ responsável pela síntese das globinas ßmajor (Hbb-b1) e ßminor ( $\mathrm{Hbb}-b 2)$, é o gene que mais se identifica com as características do mutante, localizado no cromossomo 7 a $50 \mathrm{cM}$. A deficiência deste gene leva a uma das mais severas anemias humana, a $\beta$-Talassemia major. Hemoglobinopatia genética caracterizada pela síntese reduzida de $\beta$ globina associada com anemia microcítica, hemoglobina intracelular reduzida (hipocromia), e inclusão eritrocítica dos organismos compostos pelo excesso das cadeias insolúveis de $\alpha$ globina.

Palavras chaves: 1 - Camundongo mutante; 2 - Mapeamento genético; 3 - Anemia hemolítica. 


\begin{abstract}
CRUZ, C.C. Mapeamento Genético e Caracterização Fenotípica do Mutante Anêmico Induzido por Ethyl-nitroso-urea. 2009. 103 f. Máster thesis (Biotechnology) - Instituto de Ciências Biomédicas, Universidade de São Paulo, São Paulo, 2009.
\end{abstract}

The origin of the Anaemic mutant was brought about by chemical mutagenesis using the mutagenic agent ENU (N-ethyl-N-nitrosourea), followed by phenotypic observation. At birth, this mutant was pale-colored and smaller-sized than the other normal mice in the same litter. Inheritance-type is auto-somic dominant, with intra-uterus death of the mutant homozygotes. After establishing mutant lineage on a BALB/c base, BALB/c Anaemic $($ Anem/+) and C57BL/6 (+/+) mice were crossed for genetic mapping, these generating F1 hybrid mutants, which on being re-crossed with their normal parent, gave rise to the N2 generation used in the mapping. Identification of Anaemic heterozygotic animals was done by reticulocit count, which placed in evidence intense reticulocitosis as a consequence of cronic haemolitic anaemia. The analysis of haematologic parameters was undertaken for phenotypic characterization of the Anaemic mutant, besides other analyses, namely, direct and total bilirrubin, seric iron and the capacity to bond with iron, histological analysis of bone marrow, the splean, liver, kidneys and 18-day-old foetuses, and the morphological analysis of erithrocites through scanning electronic microscopy. Haemolitic assay of the Complementary System was carried as part of immunological analysis. Haemostasia techniques, such as protombin time and activated partial tromboplastin time were also undertaken.Haemoglobin electrophoresis was performed to detect deficiencies in its production. The Aenemic mutant presented splenomegaly, reticulocitosis and accentuated polycromasy, this indicating the existence of cronic haemolitic anaemia and an increase in eritropoiesis, the usual response to anaemia and hypoxemy, thus inducing the precocious release of cells from the bone marrow, as well as a marked microcitosis and accentuated hypocromy, the deficiency in the synthesis of haemoglobin thereby becoming clearly defined. From histological analysis, hemossiderosis was apparent in all the organs analyzed as well as extra-medular eritropoiesis in the spleen and liver. Genetic mapping was carried out by means of micro-satellite markers, from which polymorphic markers were selected among those BALB/C and C57BL/6 lineages involved in the mapping. A panel of the micro-satellites distributed throughout the whole mouse genome was established, in such a way as to permit localizing the mutation-bearing chromosome. In the first place, a strong bond between the mutant gene and the markers in chromosome 7 was found. Additional tests were then carried out, using additional markers from the same chromosome with the aim of establishing a highly trustworthy bond. On seeking recombinants that indicated a positional candidate, the D7Mit301 and D7Mit131 markers between $46,5 \mathrm{cM}$ and $51 \mathrm{cM}$ gave evidence of an interval of 4,5cM containing 106 genes with known functions. Through phenotypic analysis of the Anemic mutant and studies of the candidate genes in this interval, it became evident that the $\mathrm{Hbb}$ gene responsible for the sythesis of the Bmajor (Hbb-b1) and Bminor ( $\mathrm{Hbb}-\mathrm{b} 2)$ globins, and located in chromosome 7 at $50 \mathrm{cM}$, is that which better identifies with the mutant characteristics. Deficiency in this gene leads to one of the most severe forms of human aenemia, $\beta$ Talassemia major - genetic haemoglobinopathy, characterizied by reduced synthesis of $\beta$ globine, associated with microcitic aenemia, reduced intracellular haemoglobine (hypochromy), and eritrocitic inclusion of compound organs through the excess of insoluble chains of a globin.

Keywords: 1 - Mutant mouse; 2 - Genetic mapping; 3 - Haemolitic aenemia. 


\section{INTRODUÇÃO}

A Biotecnologia se embasa e interage intensamente com as Ciências Biológicas, especialmente, a Bioquímica, a Biofísica, a Fisiologia, a Genética, a Microbiologia, a Virologia, a Parasitologia, a Farmacologia e a Imunologia entre outras. Todas estas áreas são utilizadas como disciplinas instrumentais na manipulação de microorganismos, bem como na de células e tecidos vivos de animais e de plantas. A Biotecnologia vale-se também de outras disciplinas (Ecologia, Botânica, Zoologia) na seleção de seres vivos naturais diretamente úteis, ou que sejam bons candidatos para manipulação genética final; e tem importantes correlações com a Química Fina, especialmente no tocante à Química de Produtos Naturais e na Engenharia Molecular.

Claramente, o ponto em comum das Biotecnologias Modernas é a utilização de técnicas sofisticadas e inovadoras de obtenção e de manipulação do ser vivo produtor. O desenvolvimento destas técnicas e da capacidade de inovação neste setor de ponta é um item crítico da estratégia de modernização progressiva e competitividade crescente do enorme mundo das Biotecnologias.

A existência de uma enorme quantidade de periódicos científicos especializados e um respeitável número de artigos publicados periodicamente celebra a importância e o impacto da pesquisa da vida sobre o cotidiano do homem. Uma justificativa forte para este crescimento está na necessidade de se conhecer como as proteínas, açúcares, lipídios e ácidos nucléicos, considerados blocos básicos de construção, interagem entre si em suas vias metabólicas e regulam a fisiologia própria dos tecidos que compõem os órgãos e sistemas de mamíferos superiores. Adquirir este tipo de informação é crucial para se tentar resolver outra questão importante: compreender as causas orgânicas e inorgânicas envolvidas no estabelecimento das doenças moleculares no homem e nos animais, permitindo o desenvolvimento de terapias que possam trazer a cura. A última meta para o estudo da genética humana tem sido identificar e caracterizar genes contribuindo para a particular condição patológica, eventualmente liderando as investigações para terapias alvo (GODINHO, 2006). 
A maioria dos estudos de função gênica envolve o uso de organismosmodelo que recapitulam patologias humanas. Dentre os organismos utilizados estão leveduras, Drosophila melanogaster, Caenorhabditis elegans, cães, gatos, ratos; no entanto, o camundongo é o organismo-modelo de maior escolha. O uso do modelo animal na pesquisa é essencial para entender o processo e como os genes se interagem no sistema biológico e no organismo como um todo (GODINHO, 2006).

O camundongo é uma ferramenta experimental versátil para estudos de doenças genéticas. É de fácil manipulação e se adapta bem a condições artificiais de criação em laboratório. Várias linhagens isogênicas estão disponíveis e é possível fazer cruzamentos controlados a partir de linhagens interespecíficas que normalmente geram proles viáveis e férteis, tornando possível a análise de segregação de vários tipos de polimorfismos (GUÉNET, 1998). Além disso, o homem e o camundongo compartilham o período de divergência evolutiva mais recente, em comparação com outros modelos tais como Drosophila, a mosca de frutas doméstica, e Xenopus (GUÉNET, 2003).

Uma comparação dos dados genômicos obtidos do seqüenciamento completo dos genomas murino e humano (WATERSTON et al., 2002; LANDER et al., 2001) levou ao achado de que mais de $99 \%$ dos genes em camundongos têm homólogos no homem (AUSTIN et al., 2004). Mais de 90\% dos dois genomas podem ser alinhados em regiões de sintenia conservada entre as duas espécies. A proximidade genômica entre o homem e o camundongo é um fator marcante que incentiva a adoção dos modelos murinos como meio experimental nos estudos de patologias humanas. Embora outros organismos modelos possam ser utilizados com facilidade em processos de dissecção genética, o camundongo continua sendo o modelo mais valorizado hoje em estudos genéticos envolvendo aspectos comportamentais, desenvolvimento embrionário de mamíferos, câncer e imunologia (PERKINS, 2002).

Uma nova comparação feita entre os genomas no homem e camundongo possibilitou a revisão de dados de genes e proteínas ora catalogados (CHRURK et 
al., 2009). O estudo concluiu que $75 \%$ dos genes do camundongo são ortólogos aos genes humanos, mantendo as funções ancestrais em ambas as espécies e, portanto, sendo alvos apropriados ao estabelecimento de modelos de doenças. Dados fenotípicos de 5.000 destes 15.187 genes já existem, tendo sido obtidos principalmente pelo estudo de camundongos knock-out. Outros genes existem em múltiplas cópias no genoma do camundongo B6 e são polimórficos entre as linhagens de camundongos, sendo mais difíceis de estudar em base gene a gene. Enquanto a variação entre linhagens sugere que alguns desses genes linhagem específicos não são essenciais para o desenvolvimento, muitas destas diferenças podem contribuir para a variação fenotípica observada entre as linhagens de camundongos. A compreensão das inovações específicas dos camundongos são, entretanto, críticas na investigação da fisiologia humana ou de doenças na utilização do camundongo como organismo modelo. Desta forma, esta nova revisão do seqüenciamento do camundongo, auxilia na compreensão da biologia específica do camundongo e permite o delineamento de funções biológicas ancestrais que são divididas com o homem, distinguindo-as das que não o são.

A importância do camundongo na modelagem de doenças humanas se materializa em inúmeros mutantes murinos espontâneos e induzidos que são constantemente recuperados pelos geneticistas de camundongos. A coleção atual de mutações cobre alterações em praticamente todas as classes fenotípicas. Um grande número de mutantes apresenta fenótipos homólogos aos observados em doenças humanas, que em grande parte dos casos se estendem a nível molecular (GUÉNET, 1998).

Um benefício adicional do camundongo como organismo modelo é a habilidade de se controlar a sua genética. Existe uma ampla variedade de linhagens isogênicas de camundongos disponíveis que podem ser controladas geneticamente. Além disso, seus embriões podem ser manipulados permitindo uma super expressão ou expressão reduzida de alguns genes através da produção de camundongos transgênicos e camundongos 'knock-out'. 
A publicação da seqüência completa do genoma do camundongo possibilitou um grande avanço nos estudos de função gênica (WATERSTON et al., 2002). Isso consolidou o camundongo como melhor modelo animal para distúrbios humanos, ao mostrar a grande similaridade entre os dois genomas. O genoma murino possui 2,66 gigabases distribuídas em seus 19 autossomos, sendo pouco menor que o humano. As regiões conservadas no genoma humano são encontradas espalhadas por todo o genoma do camundongo, e suas similaridades facilitam os estudos de identificação e localização de genes em ambas as espécies (REW, 2003).

Existem modelos animais para várias doenças humanas, dentre elas a Síndrome de Waardenburg, Síndrome de Usher, nanismo, obesidade (MOORE, 1999). Outro modelo animal importante para o estudo de doenças humanas é mutante natural nude, autossomo recessivo. O gene whn isolado através da clonagem posicional é responsável pela iniciação e manutenção de diferentes fenótipos de células epiteliais do timo (SHORPP, 1997). A mutação pleiotrópica causa a falta total de pêlos, ausência do timo com uma grande carência de células T do sistema imune e mostra baixa fertilidade (SCHLAKE, 2001).

\subsection{Linhagens isogênicas e suas vantagens}

Uma linhagem isogênica é estabelecida através de um esquema de cruzamentos entre irmãos e, é considerada isogênica após 20 gerações de cruzamentos sucessivos, quando $99,9 \%$ do genoma estão em homozigose e, é idêntico para todos os indivíduos da linhagem (PANTHIER et al., 2003). As linhagens apresentam características que diferem umas das outras e uma uniformidade fenotípica entre os indivíduos de uma mesma linhagem, o que permite afirmar que as variações experimentais são resultados apenas de fatores externos, sem comprometimento genotípico do animal. Por fim, a linhagem isogênica deve apresentar uma estabilidade genética ao longo do tempo, possibilitando que um experimento seja repetido entre animais de diferentes 
laboratórios (BENAVIDES et al., 2004).

No estabelecimento de uma linhagem isogênica, a prole que resulta de um acasalamento entre dois irmãos F1 é denominada de segunda geração filial ou animais F2; e um acasalamento entre dois irmãos F2 produzirá animais F3 e assim sucessivamente. Em cada geração filial subseqüente, a homogeneidade genética entre os irmãos é lentamente estabelecida num processo referido como endogamia. Esse processo levará à produção de camundongos endogâmicos que são geneticamente homogêneos e homozigotos em todos os loci (Commitee on Standardized Genetic Nomenclature for Mice, 1989).

As vantagens geradas pela diversidade de linhagens isogênicas recaem tanto na uniformidade genética, dentro de uma linhagem, como na diversidade genética própria da rica coleção de linhagens isogênicas amplamente disponíveis. Linhagens isogênicas nos permitem observar condições experimentais repetidamente num fundo (background) genético uniforme. Além disso, cruzamentos entre as linhagens proporcionam oportunidade de se observar efeitos de genes modificadores - ponto principal da genética de organismos modelo (HAMILTON e FRANKEL, 2001).

Benavides e colaboradores em 2004 relacionaram cerca de 480 linhagens de camundongos, mantidas em laboratórios em todo o mundo, sendo as principais linhagens isogênicas: $B A L B / c, C 3 H, C 57 B L / 6, C B A, D B A / 2, C 57 B L / 10, A K R, A / J$, 129, SJL, entre outras. O número de linhagens de camundongos cresce exponencialmente com $\mathrm{o}$ estabelecimento de linhagens geneticamente modificadas.

\subsection{Indução de mutações por ENU}

Algumas variedades de mutações espontâneas foram identificadas pela estratégia fenótipo dirigidas, o que levou à caracterização de modelos animais importantes. Entretanto, o fato destas ocorrerem com uma freqüência relativamente baixa exigiu o desenvolvimento de métodos que acelerassem a 
obtenção de novos mutantes. Uma das formas de gerar mutações em larga escala se dá através de agentes mutagênicos químicos como o alquilante ENU ( $\mathrm{N}$-ethyl$\mathrm{N}$-nitrosourea), considerado o mais potente agente mutagênico em camundongo (RUSSELL, 1979 in BALLING, 2001). ENU vem sendo largamente utilizado na tentativa de se gerar mutações em camundongos.

ENU é um poderoso agente mutagênico e, através de seu uso, é possível a geração de inúmeras mutações em diferentes partes do genoma do camundongo. A vantagem das mutações pontuais reside na possibilidade de alterações gradativas no gene, proporcionando um aprofundamento e detalhamento nos estudos que envolvem função. Outra aplicabilidade do ENU é trazer a tona genes modificadores ainda desconhecidos, já que mutações aleatórias por ENU estão desvinculadas do conhecimento prévio da localização e da seqüência dos genes.

O grupo ethyl do ENU pode transferir os sítios de nucleotídeos $\mathrm{N} 1, \mathrm{~N} 3$, ou N7 para grupos de adenina; o O6, N3, ou N7 para guanina; o O2, O4, ou N3 para timina; e o $\mathrm{O} 2$ ou N3 para citosina. Como resultado forma-se o DNA aduzido, com erro de pareamento e ocorre substituição de par-base durante a próxima etapa de replicação do DNA. A mutação mais comum induzida por ENU é a inversão por AT para TA e a transição de AT para GC. Mais de $82 \%$ das mutações seqüenciadas mostram estes tipos de mutações, a provável parte do resultado de erro do pareamento é a alquilação de $\mathrm{O} 4$ e $\mathrm{O} 2$ para timina. Assim, a administração de ENU pode levar ao aparecimento de mutações pontuais no genoma ocasionando perda parcial de função, alterações na função ou mutações dominantes negativas. Esta é uma característica interessante já que muitas doenças genéticas humanas têm como origem mutações de base única (BALLING, 2001).

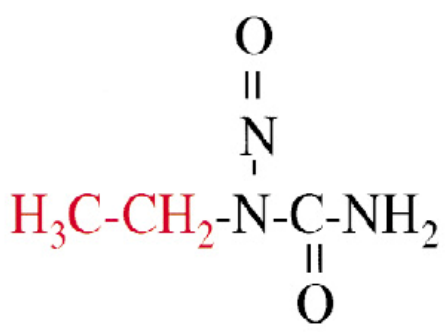


Figura 1- Estrutura de N-ethyl-N-nitrosourea (ENU) com o grupo ethyl transferível marcado em vermelho.

ENU não é somente mutagênico, mas também tóxico. Por esta razão, os tratamentos devem equacionar dose e tempo de exposição de forma a alcançar um equilíbrio entre a alta freqüência de mutação e a baixa toxicidade. ENU é também um potente carcinógeno, podendo originar vários tipos de tumores em camundongos apesar de sua eficiência na mutagenização espermatogonial em camundongos (FLAHERTY, 1998).

Quando administrados em grandes doses os agentes químicos podem causar esterilidade permanente. É de extrema importância que a dose e a freqüência com que estes agentes são administrados sejam bem controladas, de forma a potencializar sua capacidade mutagênica sem causar infertilidade no animal (FLAHERTY, 1998). Injeções de ENU em camundongos machos geralmente levam a uma diminuição no número de espermatogônias, o que resulta em um período de esterilidade que dura cerca de 14 semanas (BALLING, 2001). É importante ressaltar que nem todas as linhagens reagem igualmente ao tratamento por ENU, podendo ocorrer esterilidade permanente ou até mesmo a morte dos animais (BALLING, 2001).

A comunidade científica que estuda genética de camundongos reconheceu ser possível a criação de uma coleção de linhagens de camundongo com uma mutação em cada gene do genoma (JACKSON, 2001). De posse de cada um desses animais, pode-se buscar por modelos válidos de desordens humanas, naqueles cuja homologia genética e semelhança fenotípica estiverem bem estabelecidas e relacionadas entre as duas espécies. Programas de mutagênese com ENU podem colaborar nesse esforço, estando distribuídos por todo o mundo. O "National Institut of Health" (NIH) criou projetos que procuram por mutações dominantes e recessivas que afetem o desenvolvimento, funções do sistema nervoso e comportamentos complexos (GRAHAM et al., 2001).

A estratégia de utilização de ENU é dita fenótipo dirigida, ou foward 
genetics, que se baseia na busca de uma mutação através da observação de um fenótipo.

\subsection{Tipos de Cruzamentos}

Para a localização de uma mutação identificada pelo fenótipo é necessário produzir cruzamentos nos quais a mutação e os marcadores genéticos polimórficos se combinem. Após a escolha de uma linhagem geneticamente distinta da linhagem portadora da mutação, estabelece-se um intercruzamento produzindo-se uma geração F1. Numa segunda etapa é feito um retrocruzamento dando origem a uma geração $\mathrm{BC} 1$, na qual $50 \%$ dos indivíduos apresentam o fenótipo, mas todos os indivíduos são informativos para o mapeamento mesmo apresentando informações sobre uma só cópia do cromossomo. Por outro lado pode-se fazer um intercross a partir da geração F1 originando uma geração F2 na qual $25 \%$ dos indivíduos apresentam o fenótipo, mas que por outro lado apresentam duas meioses informativas. Para se obter a mesma resolução precisam-se duas vezes mais animais de um retrocruzamento que de um intercruzamento.

Para se localizar uma mutação numa região cromossômica, produz-se geralmente 50 indivíduos descendentes de um retrocruzamento ou 25 indivíduos de um intercruzamento, que permitem obter uma resolução de $4 \%$ de recombinação, aproximadamente $8 \mathrm{Mb}$ que comporta em média 80 genes. Para a clonagem posicional com resolução média de $0,1 \%$ de recombinação (200 kilobases no camundongo) é necessário produzir por volta de 1000 mutantes (SILVER, 1995). 


\subsection{Mapeamento genético}

O mapeamento é feito a partir da análise de ligação entre um marcador e o locus de interesse. Esta análise é feita com base no padrão de segregação entre os loci através das gerações. As Leis de Mendel afirmam que dois loci não ligados possuem segregação independente. Dessa forma, a probabilidade de uma geração herdar o haplótipo parental, em um cruzamento-teste, é sempre $50 \%$. É observada ligação quando essa probabilidade se desvia de $50 \%$, devido a um excesso de haplótipos parentais. Isso ocorre porque os loci estão ligados, ou seja, estão muito próximos um do outro, tornando raros eventos de recombinação entre eles (BOYD, 1998).

O mapeamento genético depende de dois fenômenos biológicos básicos:

1- O processo de recombinação (ou crossing over) que ocorre durante a divisão de células meióticas para a produção de gametas;

2- A variação genética natural ou induzida entre as linhagens de camundongos.

Os microssatélites são os marcadores mais utilizados em estudos de mapeamento genético. São repetições em tandem de pequenas seqüências de DNA, e se encontram espalhados por todo o genoma de quase todos os organismos existentes. Esses elementos de repetição possuem aproximadamente 2 a 8 nucleotídeos (CHAMBERS et al., 2000). Os microssatélites estão amplamente distribuídos no genoma do camundongo e isso facilita o mapeamento de loci localizados em qualquer região cromossômica. A seleção dos microssatélites para o mapeamento é feita de acordo com os indícios dos cromossomos na homozigose estabelecendo-se um painel de marcadores que permita a localização do cromossomo portador da mutação. Uma vez encontrada uma ligação entre o gene mutante e um marcador são feitos testes adicionais utilizando-se mais marcadores do mesmo cromossomo com o objetivo de estabelecer a ligação com alto grau de confiança. Depois que o lócus foi estabelecido em uma região cromossômica de 20 a 30 cM são testados 
marcadores adicionais dentro deste intervalo com o objetivo de refinar a posição no mapa (CHAMBERS et al., 2000).

A principal aplicação do mapeamento genético é a identificação de genes candidatos para fenótipos mutantes - também chamados de "candidato posicional".

A unidade de medida utilizada em um mapa genético é o centimorgan (cM) 1 cM corresponde a 1\% de recombinação (BOYD, 1998). Um mapeamento é considerado de alta resolução quando são observados eventos de recombinação entre o marcador e o locus distantes em 0,1 cM. Para que seja possível observar estes eventos muitas vezes torna-se necessário testar um grande número de animais, para que a probabilidade de um deles apresentar esse haplótipo aumente. O mapeamento é a construção de mapas através do uso de marcadores herdados. É também chamado de mapeamento de recombinação ou análise de ligação (BOYD, 1998). O mapeamento permite delimitar a região cromossômica onde se encontra a mutação estudada. Através dele também é possível descobrir se este trata de uma segunda mutação em um gene já conhecido ou se ela encontra-se em um novo locus. Portanto, a localização da mutação no genoma pode possibilitar a seleção de regiões candidatas, que serão posteriormente analisadas por seqüenciamento e estudos de expressão gênica, para confirmá-las como responsáveis pela disfunção (BEIER et al., 2004).

Para cada mutação mapeada, um estudo de homologia entre camundongos e o homem deve ser feito na tentativa de achar um gene candidato para a mutação. No passado, caso a estratégia do gene candidato fosse confirmada, o número de animais mutantes seria aumentado para se dar início à clonagem posicional do gene responsável com a construção de um mapa genético da região de alta resolução a partir do isolamento de Yacs e Bacs para o mapa físico, seqüenciado o DNA contido no contig da região da mutação. Hoje, após o sequenciamento do genoma do camundongo essa tarefa foi simplificada, somando-se à utilização de polimorfismos de um único nucleotídeo (SNPs). A genotipagem com SNPs é particularmente adequada para a análise genética de 
organismos, como modelos murinos, pois marcadores bialélicos permanecem plenamente informativos quando utilizados para caracterizar cruzamentos entre linhagens puras (TSANG, 2005). Os dados obtidos em bancos de dados sobre o genoma do camundongo também possibilitam o sequenciamento de genes candidatos.

\subsection{Caracterização e estudo do fenótipo}

Os fenótipos mutantes observados em uma prole de camundongos tratados com ENU devem ser associados a apenas uma mutação. Desta forma, são feitos cruzamentos para gerar linhagens coisogênicas. Isolada a mutação, é importante confirmar se o caráter observado é herdável. São feitos cruzamentos para verificar se o fenótipo é realmente transmitido entre as gerações, e em qual tipo de herança ele se encaixa (autossômica dominante ou recessiva, ligada ao sexo dominante ou recessiva) (FLAHERTY, 1998).

Confirmado o caráter hereditário, os mutantes devem passar por uma rigorosa análise fenotípica para que a mutação seja caracterizada corretamente. Esta análise é feita observando-se os animais desde o nascimento até a idade adulta. Como os camundongos raramente são mantidos após seis meses de vida, a caracterização de distúrbios que aparecem numa fase mais avançada é dificultada. É necessária uma observação cautelosa, principalmente quando se deseja identificar mutações neurológicas. Alguns fenótipos são mais óbvios que outros. No entanto, algumas características são extremamente difíceis de serem identificadas, como as que causam distúrbios metabólicos, de aprendizagem ou memória, ou aquelas mutações que levam a uma morte intra-uterina ou logo após o nascimento (FLAHERTY, 1998). Deve-se também verificar se a mutação isolada é nova ou se já foi descrita.

Em geral, as mutações caracterizadas fenotipicamente em genes murinos, são mapeadas para assim definir geneticamente um locus, permitindo em seguida, 
na maioria das vezes, a identificação de genes candidatos na região mapeada (TAYLOR, 2000).

Concluída a caracterização fenotípica do mutante e determinado seu modo de herança, o interesse maior é chegar à causa do fenótipo, sendo que o próximo passo envolve localizar a mutação no genoma, verificando se a mesma está presente em um locus próximo a genes já conhecidos e que expressam um fenótipo semelhante (FLAHERTY, 1998). Esse estudo auxilia na clonagem posicional do gene responsável pela mutação.

Em nosso laboratório, ligado ao Biotério de Experimentação, do Departamento de Imunologia do ICB/ USP, em 2000 foi dado início ao projeto "O Camundongo Como Organismo Modelo - Indução de Novas Mutações" dando origem a 11 linhagens mutantes entre recessivas e dominantes induzidas por ENU, apresentando fenótipos diversos. Nesse trabalho o mutante Anêmico foi estudado em detalhes do ponto de vista genético e hematológico.

\subsection{Eritropoiese - Estágios de diferenciação}

A medula óssea contém células de origem pluripotentes que possuem duas propriedades funcionais: auto-renovação, capacidade de gerar novas células de origem, e capacidade de se diferenciar em qualquer uma das linhagens celulares do sangue. Com o início da diferenciação uma célula de origem perde seu potencial pluripotente e se torna direcionada para a produção de uma ou mais linhagens de células (RAPAPORT, 1990). Trata-se de um dos órgãos mais ativos. Em condições normais, $75 \%$ das células presentes na medula óssea pertencem à série mielóide de células produtoras de leucócitos, e apenas $25 \%$ consistem em eritrócitos em processo de maturação, apesar de existirem 500 vezes mais eritrócitos do que leucócitos na circulação. Essa diferença na medula reflete o fato de que a sobrevida média dos leucócitos é curta, enquanto a dos eritrócitos é longa (GANONG, 2006). 
Os estágios de diferenciação da hemácia (células vermelhas, eritrócito) podem ser divididos da seguinte forma:

a) células progenitoras: unidades formadoras de colônias de eritróides, onde as células eritróides progenitoras mais diferenciadas formam pequenas colônias de até 64 precursores eritróides nucleados em cultura (RAPAPORT, 1990). Por sua vez essas células progenitoras dão origem aos vários tipos diferenciados de células sanguíneas. Existem reservatórios separados de células progenitoras de megacariócitos, linfócitos, eritrócitos, eosinófilo e basófilos, enquanto os neutrófilos e monócitos originam-se de um precursor comum (GANONG, 2006);

b) normoblasto ou Proeritroblasto: precursores nucleados morfologicamente reconhecíveis. A célula perde seus nucléolos e se vê uma aglutinação inicial de cromatina do núcleo, o citoplasma possui elevado conteúdo de RNA;

c) reticulócito: a célula, agora quase madura, já expeliu o núcleo. No entanto, ainda contém RNA residual em seu citoplasma, que pode ser precipitado sob a forma de uma rede de reticulina por certos corantes supravitais. É isto que lhe dá o nome de reticulócito. A coloração para a rede de reticulina é usada para distinguir o reticulócito da hemácia completamente madura. Quando a produção de eritrócitos é estimulada por quantidades crescentes de eritropoetina, os reticulócitos recémformados são liberados para circulação sem o amadurecimento prévio de 1 a 2 dias na medula. Portanto, eles contêm RNA precipitável e se coram como reticulócitos durante 2 a 3 dias;

d) hemácias: eritrócitos já maduros são redondos, com pequena variação de tamanho. Uma área de palidez central é vista na maioria das células porque o eritrócito normal é um disco bicôncavo. Nos seres humanos, apresentam uma sobrevida média de 120 dias na circulação (RAPAPORT, 1990). 


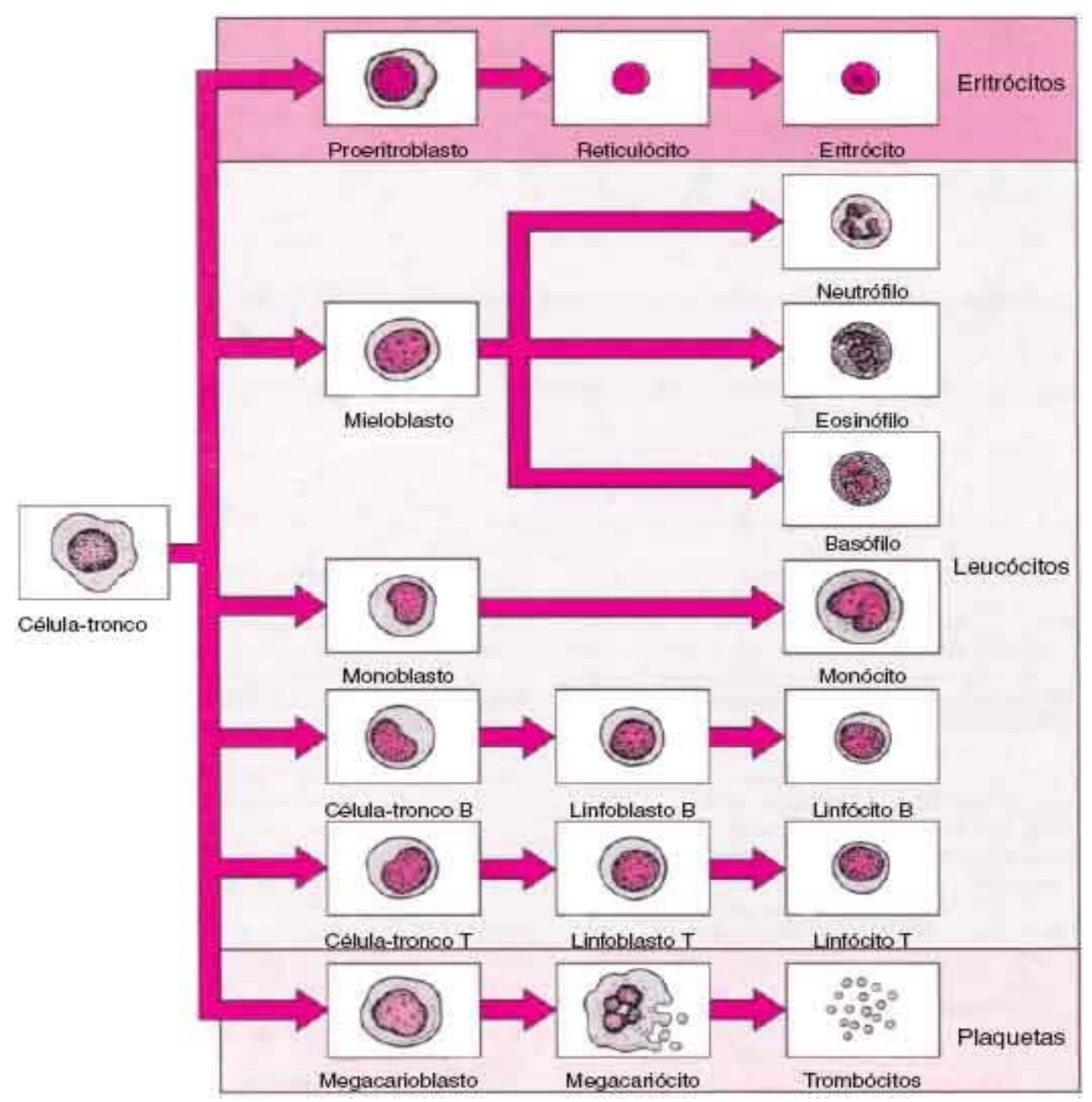

Figura 2- Esquema do desenvolvimento celular a partir de células tronco (RAPAPORT, 1990).

\subsection{Líquidos corporais circulantes - Circulação}

O sistema circulatório é o sistema de transporte que fornece aos tecidos oxigênio (O2) e as substâncias absorvidas do trato gastrintestinal, libera CO2 nos pulmões e transporta outros produtos do metabolismo até os rins, atua na regulação da temperatura corporal e distribui os hormônios e outros agentes que regulam a função celular. O sangue, que é o transportador dessas substâncias, é bombeado através de um sistema fechado de vasos sanguíneos pelo coração que, nos mamíferos, consiste, na realidade, em duas bombas dispostas em série. Os elementos celulares do sangue - leucócitos, eritrócitos e plaquetas - estão 
suspensos no plasma. O volume total circulante normal de sangue é de cerca de $8 \%$ do peso corporal. Cerca de $55 \%$ desse volume consistem em plasma (GANONG, 2006).

\subsection{Estrutura e função da hemoglobina}

O pigmento vermelho que transporta o oxigênio nos eritrócitos de vertebrados é a hemoglobina, uma proteína com peso molecular de 64.450. A hemoglobina é uma molécula globular constituída por quatro subunidades. Cada subunidade contém um heme conjugado a um polipeptídio. O heme é um derivado porfirínico que contém ferro. Os polipeptídios são descritos coletivamente como a porção globina da molécula de hemoglobina. Existem dois pares de polipeptídios em cada molécula de hemoglobina. Na hemoglobina humana adulta normal, os dois tipos de polipeptídios são denominados cadeias $\alpha$, contendo, cada uma, 141 resíduos de aminoácidos, e cadeias $\beta$, que contêm cada uma, 146 resíduos de aminoácidos (GANONG, 2006). A hemoglobina nos camundongos mus musculus, é também formada às cadeias $\alpha$, contendo, cada uma, 142 resíduos de aminoácidos, e cadeias $\beta$, com 147 resíduos de aminoácidos tendo tamanhos similares aos humanos (MGI www.informatics.jax.org).

A síntese do grupo heme ocorre nas mitocôndrias ao mesmo tempo em que as globinas $\alpha, \beta$, $\delta$ e gama são produzidos. O grupo heme é composto por um anel porfirínico no qual se acomoda em seu centro um átomo de ferro ligado a quatro átomos de nitrogênio (Figuras 3 e 4). 


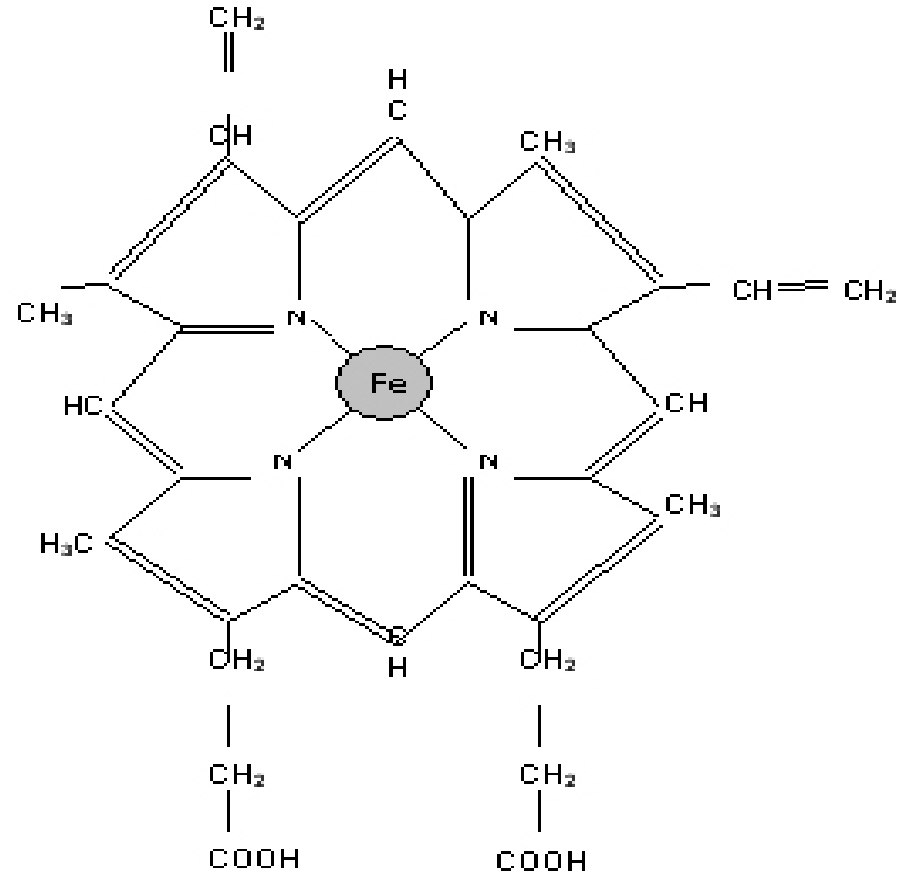

Figura 3 - O grupo heme composto pela molécula anelada de porfirina e o ferro em sua região central.

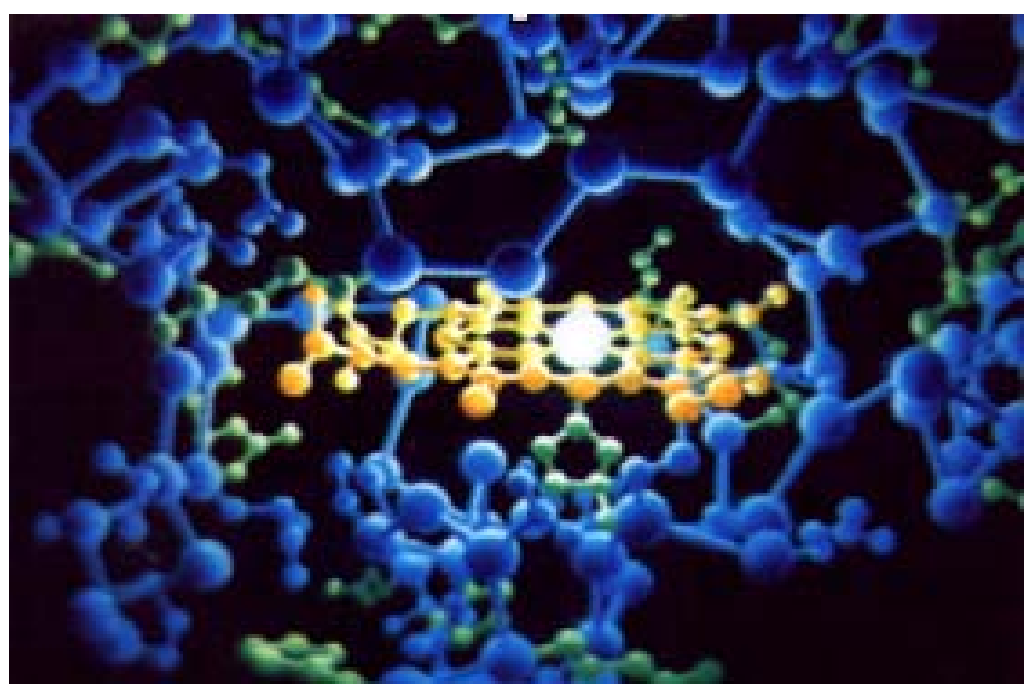

Figura 4 - Representação da estrutura molecular do grupo heme inserida na globina. No centro, a esfera maior representa o ferro circundado pelo anel de porfirina. As estruturas carbonadas mais claras indicam as posições dos aminoácidos hidrofóbicos que protegem o grupo heme da água circundante. As estruturas escuras e maiores são os aminoácidos hidrofílicos da superfície interna da globina (GANONG, 2006). 


\title{
1.9 Hemoglobinopatias - Modelos de doença molecular
}

\author{
MUTAÇÃO $\Rightarrow$ PROTEÍNA ALTERADA $\Rightarrow$ FUNÇÃO ANORMAL $\Rightarrow$ DOENÇA
}

O estudo da estrutura e evolução da hemoglobina indica que certos tipos de mutações provavelmente são patogênicos. Assim, uma mutação que altere a conformação da globina, substitua aminoácidos altamente conservados, ou desorganize o invólucro hidrófobo por troca de um dos resíduos apolares, tende a causar uma hemoglobinopatia (THOMPSON e THOMPSON, 1993).

As hemoglobinopatias ocupam uma posição singular na genética médica por várias razões. São certamente as doenças genéticas mais comuns em todo o mundo e causam morbidade significativa. A Organização Mundial de Saúde estimou que aproximadamente $5 \%$ da população mundial são portadores de genes de distúrbios clinicamente destacadas da hemoglobina, e que a cada ano nascem cerca de 350.000 homozigotos intensamente afetados ou heterozigotos compostos. A hemoglobina humana foi uma das primeiras estruturas protéicas a ser decifrada, sua patologia molecular é provavelmente mais bem compreendida do que a de qualquer outro grupo de doenças genéticas. Estas descobertas têm importância imediata para a prática médica (THOMPSON e THOMPSON, 1993).

Mutações que prejudicam acentuadamente ou evitam a síntese de uma das cadeias da globina dão origem às síndromes talassêmicas. Estas mutações podem ser de dois tipos genéricos: 1- Mutações que suprimem ou reduzem acentuadamente a síntese da cadeia sem alterar a seqüência de aminoácidos. As pequenas quantidades de cadeia polipeptídica produzidas são de estrutura normal. Estas mutações podem resultar de: a) deleção do gene, que é responsável pela maioria, mas não todos os casos de supressão de cadeia $\alpha$ ( $\alpha$ talassemia); b) substituições isoladas de base ou deleções de uma ou mais bases em um gene normal, que é responsável pela maioria dos tipos de $\beta$-talassemia. Estas mutações ocorrem em sítios importantes para a transcrição, processamento, 
estabilidade ou transporte de RNA do núcleo para o citoplasma. Nas talassemias $\beta$, acumula-se um excesso de cadeias $\alpha$ no eritrócito em desenvolvimento. Estas formam precipitados de cadeias a agregadas, que lembram corpúsculos de Heinz e que se tornam ligados a membrana celular. Os precursores eritróides em desenvolvimento contendo estes precipitados podem ser destruídos dentro da medula óssea, dando origem à eritropoiese acentuadamente ineficaz característica das $\beta$-talassemias severas. Os eritrócitos que conseguem entrar em circulação são rapidamente removidos por fagócitos mononucleares no baço. 2Mutações que tanto reduzem a síntese de cadeias quanto dão origem a uma cadeia polipeptídica anormal. Exemplo: $\mathrm{Hb}$ Lepore, um gene fundido, formado pela porção amino terminal do gene alfa e a porção terminal carboxi do gene beta (RAPAPORT, 1990).

Outras hemoglobinopatias como a anemia falciforme e a esferocitose atinge grande parte da população. Aproximadamente $8 \%$ dos negros americanos portam o traço falciforme, o que significa que a chance estatística dos portadores casarem entre si e darem origem a um bebê homozigoto para anemia falciforme é de aproximadamente 1:650 (RAPAPORT, 1990).

\subsection{Imunidade - O Sistema do Complemento}

Os efeitos da imunidade inata e adquirida na destruição de células são mediados, em parte, por um sistema de enzimas plasmáticas originalmente denominadas sistema do complemento, visto que "completavam" os efeitos dos anticorpos. A nomenclatura das mais de 30 proteínas que compõem o sistema é confusa, visto que consiste em uma combinação de letras e números, como, por exemplo, C1q, C3 e C3b. O sistema é ativado por três vias ou cascatas diferentes de enzimas: a via clássica, deflagrada por imunocomplexos; a via da lectina de ligação de manose, desencadeada quando a lectina liga-se a grupos de manose nas bactérias; e a via alternativa ou da properdina, desencadeada pelo contato com diversos vírus, bactérias, fungos e células tumorais. As proteínas produzidas 
desempenham três funções: ajudam a eliminar os microrganismos invasores por opsonização, quimiotaxia e lise final das células; atuam, em parte, como ponte entre a imunidade inata e a adquirida ao ativar as células $B$ e ao auxiliar a memória imunológica; e ajudam a eliminar os produtos de degradação após o apoptose. A lise celular, que constitui uma das principais maneiras pelas quais 0 sistema do complemento destrói as células, é produzida pela inserção de proteínas denominadas perforinas nas membranas celulares. Essas proteínas criam orifícios, que permitem o livre fluxo dos íons, com ruptura da polaridade da membrana (GANONG, 2006).

\subsection{Hemostasia - Resposta à lesão}

A hemostasia é o processo de formação de coágulos nas paredes dos vasos sanguíneos lesados e de prevenção da perda de sangue ao mantê-lo em estado líquido dentro do sistema vascular. Existe um conjunto de mecanismos sistêmicos inter-relacionados complexos, que operam para manter esse equilíbrio entre a coagulação e a anticoagulação. Além disso, o equilíbrio é afetado por fatores locais em vários órgãos diferentes.

Quando um pequeno vaso sanguíneo é danificado, a lesão desencadeia uma série de eventos que levam à formação de um coágulo. O coágulo fecha a região lesada e impede a perda adicional de sangue. $O$ incidente inicial consiste na constrição do vaso e na formação de um tampão hemostático temporário de plaquetas, desencadeado quando as plaquetas ligam-se ao colágeno e sofrem agregação. Esse processo é seguido pela conversão do tampão em coágulo definitivo pela fibrina. O mecanismo da coagulação responsável pela formação de fibrina envolve uma cascata de reações em que ocorre a ativação das enzimas inativas, que, por sua vez, ativam outras enzimas inativas. A conversão do fibrinogênio em fibrina é catalisada pela trombina. A trombina é uma serina protease que é formada a partir de seu precursor circulante, a protrombina, pela ação do fator $X$ ativado. Exerce outras ações, incluindo ativação das plaquetas, 
das células endoteliais e dos leucócitos mediante pelo menos um receptor acoplado à proteína G.

O fator $X$ pode ser ativado por reações em um de dois sistemas: o sistema intrínseco e o sistema extrínseco (Figura 5). A reação inicial no sistema intrínseco consiste na conversão do fator XII inativo em fator XII ativo. O sistema extrínseco é desencadeado pela liberação de tromboplastina tecidual, uma mistura de proteína-fosfolipídio que ativa o fator VII (GANONG, 2006).

\section{Vla intrínseca}

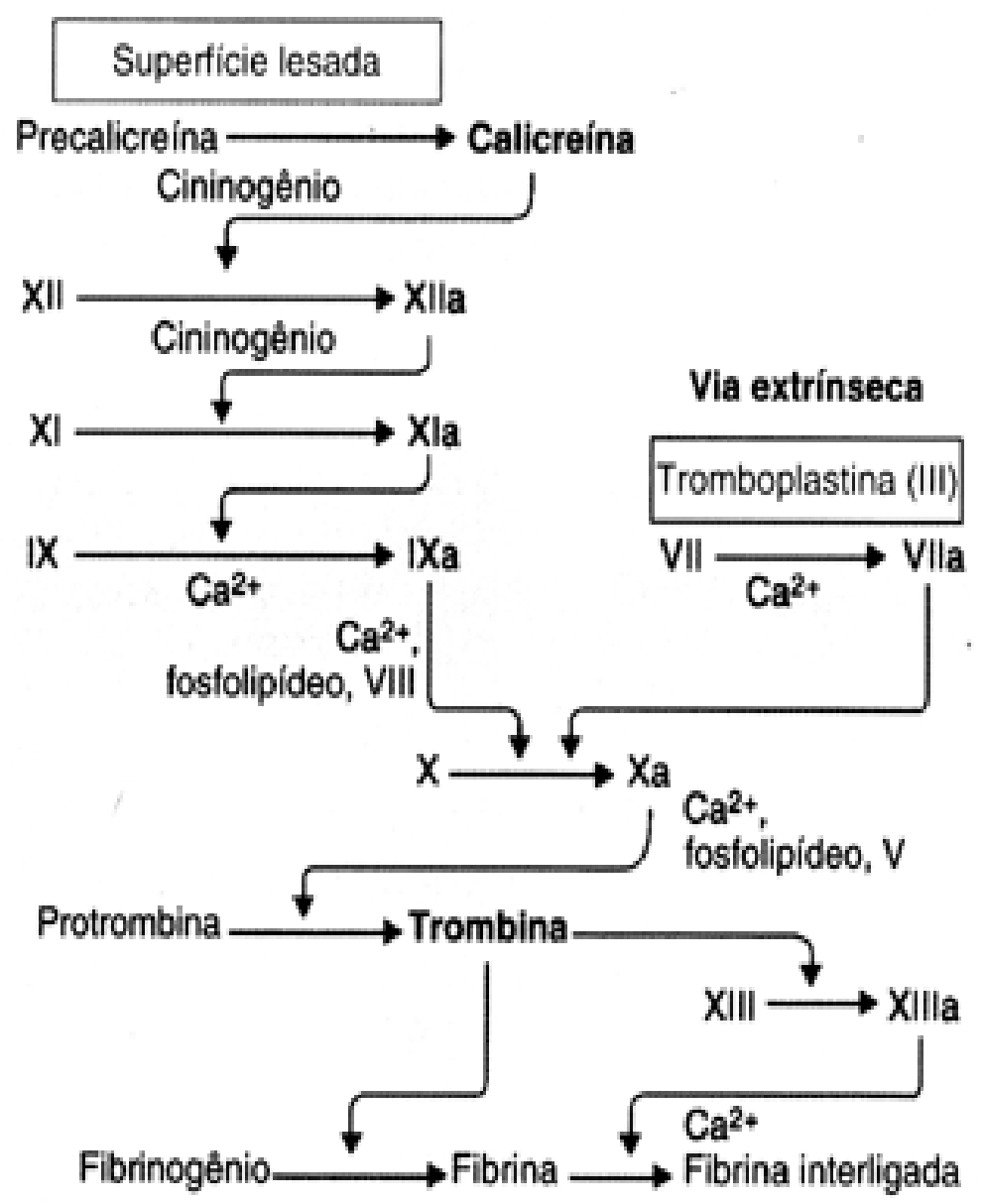

Figura 5 - O mecanismo da coagulação nas vias intrínseca e extrínseca. 


\section{CONCLUSÂO}

Nesse trabalho o mutante Anêmico foi estudado em detalhes do ponto de vista genético e hematológico

O gene mutante responsável pela mutação foi localizado no cromossomo 7, através do estudo de análises de ligação utilizando-se marcadores microssatélites. Com os dados obtidos ordenou-se os marcadores utilizados e foram buscados novos marcadores polimórficos, situados dentro da região estabelecida para favorecer o estreitamento da região. Posteriormente foi feita a verificação dos genes já mapeados na região delimitada na busca por possíveis candidatos à mutação, considerando-se a homologia entre homem e camundongo, buscando regiões humanas complementares à região murina portadora da mutação. Finalmente foi feita a verificação dos genes já mapeados na região homóloga humana e definido como gene candidato Hbb-b1. Foi ainda iniciado o seqüenciamento do gene candidato.

A caracterização fenotípica do mutante Anêmico através de técnicas hematológicas mostrou anemia hemolítica severa, esplenomeglia, reticulocitose, alteração na morfologia erotrocitária. Além dos aspectos hematológicos o estudo histológico mostrou depósito de ferro (hemossiderose) em diversos órgãos e na medula óssea, hematopoiese extramedular com metaplasia óssea evidenciada no baço, hipercelularidade da medula óssea e morte intrauterina de fetos homozigotos para a mutação. 


\section{REFERÊNCIAS BIBLIOGRÁFICAS*}

AUSTIN, C.P. et al. The Knockout Mouse Project. Nature Genetics, v. 36, n. 9, p. 921-924, 2004.

BALLING, R. ENU Mutagenesis: Analyzing Gene Function in Mice. Annual Reviews of Genomics in Human Molecular Genetics. v. 2, p. 463-492, 2001.

BEIER, D.R., HERRON, B.J. Genetic mapping and ENU mutagenesis. Genetics, v. 122, p. 65-69, 2004.

BENAVIDES, F.F.; GUÉNET, J.L. Manual de genética de roedores de laboratório: Princípios básicos y aplicaciones. Madrid: Universidad de Alcalá, 2004. p. 312.

BOYD, Y. Genetic Mapping of the mouse genome. A Companion to Methods in Enzymology, v. 14, p. 120-134, 1998.

BRASCH, R. C.; WESBEY, G. E.; GOODING, C. A.; KOERPER, M. A. Magnetic resonance imaging of transfusional hemosiderosis complicating thalassemia major. Radiology, v. 150, p. 767$771,1984$.

BRECHER, G. New Methylene Blue as a reticulocyte stain. American Journal of Clinical Pathology, v. 19, p. 895-896, 1949.

CHAMBERS, G.K.; MACAVOY, E.S. Microsatellites: consensus and controversy. Comparative Biochemistry and Physiology, v. 126, p. 455-476, 2000.

CIAVATTA, D.J.; RYAN, T.M.; FARMER, S.C.; TOWNEST, T.M. Mouse model of human g30 thalassemia: Targeted deletion of the mouse $\beta$ major e $\beta$ minor globin genes in embryonic stem cells. Genetics, v. 92, p. 9259-9263, 1995.

COHEN, A. R.; GALANELLO, R.; PENNELL, D. J.; CUNNINGHAM, M.J.; VICHINSKY, E. Thalassemia. Hematology, v. 1, p. 14-34, 2004.

COMMITEE ON STANDARDIZED GENETIC NOMENCLATURE FOR MICE. Rules and guidelines for gene nomenclature. Genetic Variants and Strains of the Laboratory Mouse. p. 1-12, 1989. In: SILVER, Lee M. Mouse genetics: concepts and applications. New York: Oxford University Press, 1995. p. 362.

FIMLS, A.S. A combined theoretical \& technical approach. Hematology, p. 423, 1989.

FLAHERTY, L. Generation, Identification and Recovery of Mouse mutations. A Companion to Methods in Enzymology, v. 14, p. 107-108, 1998.

GANONG, W. F. Fisiologia Médica. 22. ed. Rio de Janeiro: McGraw-Hill, 2006.

GODINHO, S. I. H.; NOLAN, P. M. The role of mutagenesis in defining genes in behaviour. European Journal of Human Genetics; v. 14, p. 651-659, 2006.

\footnotetext{
" De acordo com:

ASSOCIAÇÃO BRASILEIRA DE NORMAS TÉCNICAS. NBR 6023: Informação e documentação: referências: elaboração. Rio de Janeiro, 2002.
} 
GOLDBERG, S.Z.; KUEBBINGT, D.; TRAUBERT, D.; SCHAFER, P.M.; LEWIS, S.E.; POPPVA, R.A.; FRENCH, A.W. A 66-base pair insert bridges the deletion responsible for a mouse model of $\beta$-thalassemia. The journal of biological chemistry, v. 261, p. 12368-12374, 1986.

GRAHAM, B., BATTEY, E., JORDAN, E. Report of second follow-up workshop on priority setting for mouse genomics. Mammalian Genome, v. 12, p. 1-2, 2001.

GUÉNET, J.L. Animal Models of Human. Genetic Diseases,.v. 19, p. 1-15, 1998.

GUÉNET, J.L. Chemical mutagenesis of the mouse genome: an overview. Genetics, v. 122, p. 924, 2004.

GUÉNET, J.L.; BONHOMME F. Wild mice: an ever-increasing contribution to a popular mammalian model. TRENDS in Genetic, v. 19, n.1, p. 24-31, 2003.

HAMILTON, B. A.; FRANKEL, W. N. Of mice and genome sequence. Cell, v. 107, p. 13-16, 2001.

HARLEMAN, J.H. The haemoglobin types of mice. Laboratory Animals, v. 11, p. 105-108, 1977.

HUBBARD, T.; ANDREWS, D.; CACCAMO, M.; CAMERON, G.; CHEN, Y.; CLAMP, M.; CLARKE, L.; COATES, G.; COX, T.; CUNNINGHAM, F.; CURWEN, V.; CUTTS, T.; DOWN, T.; DURBIN, R.; FERNANDEZ, S. X. M.; GILBERT, J.; HAMMOND, M.; HERRERO, J.; HOTZ, H.; HOWE, K.; LYER, V.; JEKOSCH, K.; KAHAR,I A.; KASPRZYK, A.; KEEFE, D.; KEENAN, S.; KOKOCINSCI, F.; LONDON, D.; LONGDEN, I.; MCVICKER, G.; MELSOPP, C.; MEIDL, P.; POTTER, S.; PROCTOR, G.; RAE, M.; RIOS, D.; SCHUSTER, M.; SEARLE, S.; SEVERIN, J.; SLATER, G.; SMEDLEY, D.; SMITH, J.; SPOONER, W.; STABENAU, A.; STALKER, J.; STOREY, R.; TREVANION, S.; URETAVIDAL, A.; VOGEL, J.; WHITE, S.; WOODWARK, C. \& BIRNEY E. Ensembl 2005. Nucleic Acid Research, v. 33, p. 447-453, 2005.

HUBBARD, T.; BARKER, D.; BIRNEY, E.; CAMERON, G.; CHEN, Y.; CLARK, L.; COX, T.; CUFF, J.; CURWEN, V.; DOWN, T.; DURBIN, R.; EYRAS, E.; GILBERT, J.; HAMMOND, M.; HUMINIECKI, L.; KASPRZYK, A.; LEHVASLAIHO, H.; LIJNZAAD, P.; MELSOPP, C.; MONGIN, E.; PETTETT, R.; POCOCK, M.; POTTER, S.; RUST, A.; SCHMIDT, E.; SEARLE, S.; SLATER, G.; SMITH, J.; SPOONER, W.; STABENAU, A.; STALKER, J.; STUPKA, E.; URETA-VIDAL, A.; VASTRIK, I.; CLAMP, M. The Ensembl genome database project. Nucleic Acid Research, v. 30, n. 1, p. 38-41, 2002.

JACKSON, I. J. Mouse genomics: Making sense of the sequence. Current Biology, v. 11, p. 311314, 2001.

JUNQUEIRA, L. C.U.; CARNEIRO, J. Histologia Básica. 10. ed. Rio de Janeiro: Guanabara Koogan, 2004.

KAYSSER, T.M.; WANDERSEE, J. N.; BRONSON, R. T.; BARKER, J. E. Trombosis and Secondary Hemochromatosis Play Major Roles in the Pathogenesis of Jaundiced and Spherocytosis. Blood, v. 90, p. 4610-4619, 2007.

KUMAR, K. A.; SINGH, S.; BABU, P. P. Studies on the glycoprotein modification in erythrocyte membrane during experimental cerebral malaria. Experimental Parasitology, v. 114, p. 173-179, 2006.

LANDER, E.S., et al. Inicial sequencing and analysis of the human genome. Nature, v. $409, \mathrm{n}$. 6822, p. 860-921, 2001. 
LANDER, E.S.; GREEN, P.; ABRAHAMSON, J.; BARLOW, A.; DALY, MJ.; LINCOLN, S.E.; NEWBURG, L. MAPMAKER: an interactive computer package for constructing primary genetic linkage maps of experimental and natural population. Genomics, v. 1, n. 2, p. 174-81, 1987.

LEWIS, J.; YANG, B., KIM, R., SIERAKOWSKA, H., KOLE, R., SMITHIES, O., MAEDA, N. A common human $\beta$-globin splicing mutation modeled in mice. The American Society of Hematology, v. 91, p. 2152-2156, 1998.

LEWIS, S.E., JOHNSON, F.M., SKOW, L.C., DIANA POPP, LOIS B. BARNETT, POPP, R.A mutation in the $\beta$-globin gene detected in the progeny of a female mouse treated with ethylnitrosourea. National Institute of Environmental Health Sciences, v. 82, p. 5829-5831, 1985.

LIN, W-C; CHEN, J. H.; LIN, C.H.; Shen, W.H. Rapidly progressive pancreatic lipomatosis in a young adult patient with transfusiondependent myelodysplastic syndrome. Journal of the Formosan Medical Association, v. 106, p. 676-679, 2007.

MASSIRONI, S.M.G.; REIS, B.L.F.S.; CARNEIRO, J.G.; BARBOSA, L.B.S.; ARIZA, C.B.; SANTOS, G.C.; GUÉNET, J.L.; GODARD, A.L.B. "Inducing mutations in the mouse genome with the chemical mutagen ethylnitrosourea." Brazilian Journal of Medical Biology Research, v. 39, n. 9, p. 12171226, 2006.

MOORE, K.J. Utilization of mouse models in the discovery of human disease genes. Drugs Discovery Today, v. 4, n. 3, p. 123-128, 1999.

NAGHIBI, F. et al. Effects of reagent and instrument on prothrombin times and activated partial thromboplastin times and patient/control ratios. Thrombosis and haemostasis, v. 59, p. 455-463, 1988.

PANTHIER, J.J.; MONTAGUTELLI, X.; GUENET, J.L. Les organismes modèles - Génétique de la souris. Paris: Éditions Belin, 2003. v. 12, p. 283.

PERKINS, A.S. Functional Genomics in the mouse. Functional Integrated Genomics, v. 2, p. 8191, 2002.

PETERS, J.; ANDREWS, S.J.; LOUTIT J.F.; CLEGG J.B. A mouse $\beta$-globin mutant that is an exact model of hemoglobin Rainier in man. Genetics Society of América, v. 110, p. 709-721, 1985.

PETKOV, P.M.; DING, Y.; CASSEL, M.A.; ZHANG, W.; WAGNER, G.; SARGENT, E.E.; ASQUITH, S.; CREW, V.; JOHNSON, K.A.; ROBINSON, P.; SCOTT, V.E.; WILES, M.V. An Efficient SNP System for Mouse Genome Scanning and Elucidating Strain Relationships. Genome Research, v. 14, p. 1806-1811, 2004.

RAPAPORT, S. I. Introdução a Hematologia. 2.ed. São Paulo: Roca, 1990.

REIS, E. S.; FALCÂO, D. A.; ISAAC, L. Clinical Aspects and Molecular Basis of Primary Deficiencies of Complement Component $\mathrm{C} 3$ and its Regulatory Proteins Factor I and Factor $\mathrm{H}$. Scandinavian Journal of Immunology, v. 63, p. 155-168, 2006.

REW, D.A. Of digital mice and man. European Journal of Surgical Oncology, v. 29, p. 624-627, 2003.

ROSENFELD, G. Corante pancrômico para hematologia e citologia clínica. Nova combinação dos componentes do May-Grünwald e do Giemsa num só corante de emprego rápido. Memórias do Institruto Butantan, São Paulo, v. 20, p. 329-334, 1947. 
RUSSELL, W.L.; KELLY, E.M.; HUNSICKER, P.R.; BANGHAM, J.W.; MADDUX, S.C.; PHIPPS, E.L. Specific-locus test shows ethylnitrosourea to be the most potent mutagen in the mouse. Proceedings of the National Academic Science USA, v. 76, p. 5818-5819, 1979.

RYAN, T. M.; CIAVATTA, D. J.; TOWNES, T. M. Knockout-Transgenic Mouse Model of sickle cell disease. Science, v. 278, p. 873-876, 1997.

RYAN, T.M. et al. Knockout-transgenic mouse model of sickle cell disease. Science, v. 278, p. 873, 1997.

SCHALAKE, T. The nude gene and the skin. Experimental Dermatology , v. 10, p. 293-304, 2001.

SERVAIS, G.; WALMAGH, J.; DUCHATEAU, J. Simple quantitative haemolytic microassay for determination of complement alternative pathway activation (AP50). Journal of Immunology Methods, v.140, n.1, p.93-100. 1991.

SHEHEE, W.R.; OLIVER, P.; OLIVER, S. Lethal thalassemia after insertional disruption of the mouse major adult $\beta$-globin gene. Genetics, v. 90, p. 3177-3181, 1993.

SHORPP, M.; HOFMANN, M.; DEAR, T.N.; BOEHM, T. Characterization of mouse and human nude genes. Immunogenetics, v. 46, p. 509-515, 1997.

SILVER, L. M. Mouse Genetics Concepts and Applications. New York: Oxford University Press, 1995.

SKOW, L. C.; BURKHART, B. A.; JOHNSON, F. M.; POPP, R. A.; POPP, D. M.; GOLDBERG, S. Z.; ANDERSON, W. F.; BARNET, L. B.; LEWIS, S. E. A Mouse Model for $\beta$-Thalassemia. National Institute of Environmental Health Sciences, v. 34, p.1043-1052, 1983.

TAYLOR, B. A. Mapping phenotypic trait loci. In: JACKSON, I.J.; ABBOTT, C.M. Mouse Genetics and Transgenics. New York: Oxford University Press, 2000.

THOMPSON \& THOMPSON. Genética Médica. 5.ed. Rio de Janeiro: Guanabara Koogan, 1993.

TSANG, S.; SUN, Z.; LUKE, B.; STEWART, C.; LUM, N.; GREGORY, M.; WU, X.; SUBLESKI, M.; JENKINS, N. A.; COPELAND N. G.; MUNROE, D. J. A comprehensive SNP-based genetic analysis of inbred mouse strains. Mammalian Genome, v. 16, p. 476-480, 2005.

WATERSON, R.H., et al. Initial sequencing and comparative analysis of the mouse genome. Nature, v. 420, n. 6915, p. 520-62, 2002.

WHITNEY III, J. B. Simplified Typing of Mouse Hemoglobin (Hbb) Phenotypes Using Cystamine. Biochemical Genetics, v. 16, p. 667-673, 1978.

WU, L-C.; SUN, C-H; RYAN, T. M.; PAWLIK, K. M.; REN, J; TOWNES,T. M. Correction of sickle cell disease by homologous recombination in embryonic stem cells. Blood, v. 108, p. 1183-1188, 2006.

YANG, B.; KIRBY, S.; LEWIS, J.; DETLOFF, P. J.; MAEDA, N.; SMITHIES, O. A mouse model for 10-thalassemia. Proceedings of National Academic Science USA, v. 92, p. 11608-11612, 1995. 